УДК 577.2

DOI: 10.33184/spbgb-2021-09-21.14

\title{
Вовлечённость генов медиаторов воспаления в формирование индивидуальных различий в уровне депрессивности
}

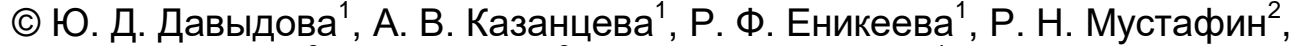 \\ М. М. Лобаскова ${ }^{3}$, С. Б. Малых ${ }^{3}$, Э. К. Хуснутдинова ${ }^{1}$ \\ ${ }^{1}$ Институт биохимии и генетики Уфимского фредерального исследовательского \\ центра Российской академии наук \\ Россия, Республика Башкортостан, 450054 г. Уфра, проспект Октября, 71, лит. 1 (E.
}

${ }^{2}$ Башкирский государственный медицинский университет

Россия, Республика Башкортостан, 450008 г. Уфра, ул. Ленина, 3.

${ }^{3}$ Психологический институт Российской академии образования

Россия, 125009 г. Москва, ул. Моховая, 9к4.

*Email: julia.dmitrievna@list.ru

Целью настоящего исследования являлась оценка основных эффректов полиморфных локусов генов TNF (rs 1041981, rs 1800629), IL6 (rs1800795) и IL6R (rs2228145), а также ген-средовых взаимодействий в френотипических вариациях уровня депрессивности у 1035 психически здоровых индивидов с учётом половой и этнической принадлежности. В результате статистического анализа был выявлен значимый модулирующий эффект таких средовых фракторов, как сезон рождения и порядок рождения, в случае ассоциации полиморфных локусов rs1041981 и rs 1800629 с уровнем депрессивности.

Ключевые слова: депрессия, депрессивность, воспаление, ген-средовые взаимодействия.

Депрессия (депрессивное расстройство, ДР) - это психическое расстройство, характеризующееся патологически сниженным настроением, торможением интеллектуальной и моторной деятельности, снижением витальных побуждений с пессимистической оценкой себя и своего положения в окружающей действительности. Как известно, ДР является многофакторной психопатологией, предрасположенность к которой определяется действием широкого спектра психологических, социальных, нейрохимических и наследственных фракторов, а также их взаимодействием между собой [1]. Согласно результатам близнецовых исследований, коэффрициент наследуемости депрессии составляет 29-46\% для различных фенотипов ДР [2], причём значительный вклад в формирование признака, наряду с моноаминергическими системами, вносит явление воспалительного процесса в организме. Об этом свидетельствуют данные о повышенной экспрессии воспалительных медиаторов, в частности С-реактивного белка острой фразы воспаления CRP (ген CRP), фрактора некроза опухоли альфа (TNF) и интерлейкинов $(I L 1 B, I L 6)$ у пациентов с депрессивным эпизодом. Это объясняется тем, что стресс любого происхождения, которому подвергаются индивиды, сопровождается ростом концентрации цитокинов в крови и повышением проницаемости гематоэнцефалического барьера. Подобные изменения приводят к способности циркулирующих в крови цитокинов проникать в мозг, запускать нейровоспалительные реакции, что может способствовать развитию ДР и других психопатологий. Вместе с тем, существуют убедительные доказательства того, что под воздействием воспалительных медиаторов зна- 
чительно снижается синаптическая доступность моноаминов, что, как известно, является одним из основных механизмов в патогенезе ДР [3].

Известно, что ряд средовых фракторов может выступать в качестве триггера для развития повышенной депрессивности посредством механизмов эпигенетической регуляции. Результаты близнецовых исследований свидетельствуют о том, что проявление фенотипа, связанного с расстройством поведения, варьируется в зависимости от места проживания (в городской или сельской местности), от характера детско-родительских взаимоотношений, этнической и половой принадлежности индивида (что может быть обусловлено различиями в деятельности нервной и эндокринной систем, в транскрипционных профилях генов мужчин и женщин), а также от других фракторов [4]. Исходя из этого, в рамках психогенетических исследований особо актуальным представляется учёт модулирующего эффректа средового компонента в анализе ассоциаций полиморфных локусов генов с исследуемым признаком.

Целью данного исследования является оценка основного эффректа полиморфных локусов генов TNF (rs1041981, rs1800629), IL6 (rs1800795) и IL6R (rs2228145), а также генсредовых взаимодействий (genexenvironment interaction, G×E) в фрормировании индивидуальных различий в уровне депрессивности у психически здоровых индивидов.

Материалы и методы исследования. В качестве материала в настоящем исследовании использовалась ДНК 1035 индивидов без наследственной отягощенности психическими заболеваниями $(79.13 \%$ женщин) в возрасте $18-25$ лет (средний возраст: $21.85 \pm 1.71$ лет) - студентов ВУЗов РФ разной этнической принадлежности (русских 344 , татар - 262, удмуртов - 224, башкир - 106, индивидов смешанной этнической принадлежности - 99). У всех индивидов была собрана инфрормация социального характера, включающая этническую принадлежность до трёх поколений, особенности детско-родительских отношений, уровень доходов семьи, место воспитания, число детей в семье и порядок рождения, наличие хронических заболеваний, табакокурения и др. Все участники заполнили добровольное согласие на участие в исследовании. Исследование было одобрено биоэтическим комитетом ИБГ УФИЦ РАН.

Для определения уровня депрессивности была использована шкала депрессии Бека (Beck Depression Inventory). Для молекулярно-генетического анализа полиморфных локусов была использована ДНК, выделенная методом фенол-хлорофрормной экстракции. Генотипирование 4 полиморфных локусов генов TNF (rs1041981, rs1800629), IL6 (rs1800795) и IL6R (rs2228145) проводилось методом ПЦР в реальном времени с использованием коммерческих наборов (LGC Genomics, UK) на амплификаторе «CFX96» (BioRad, CШA) с возможностью проведения анализа фрлуоресценции по конечной точке.

Статистическая обработка результатов включала линейный регрессионный анализ с включением половой и этнической принадлежности в качестве ковариат (PLINK v.1.9). Оценка эфрфекта ген-средовых взаимодействий была осуществлена с помощью множественного линейного регрессионного анализа, в котором в качестве независимых переменных выступали полиморфные локусы, социальные фракторы, половая и этническая принадлежность, в то время как уровень депрессивности - в качестве зависимой переменной. Стратификационный анализ был проведен с использованием непараметрического критерия Манна-Уитни (SPSS 21). Процедура FDR (False Discovery Rate) была использована для коррекции на множественность сравнений (PLINK v.1.9).

Результаты и обсуждение. Результаты оценки распределения частот аллелей и генотипов полиморфных локусов генов TNF (rs1041981, rs1800629), IL6 (rs1800795) и IL6R (rs2228145) соответствовали распределению Харди-Вайнберга ( $\mathrm{P}=0.11$ для $r s 1041981, \mathrm{P}=0.51$ для rs1800629, $\mathrm{P}=0.51$ для rs1800795, $\mathrm{P}=0.44$ для rs2228145). 
В результате линейного регрессионного анализа не было выявлено ассоциации полиморфрных локусов генов TNF (rs1041981, rs1800629), IL6 (rs 1800795) и IL6R (rs2228145) с вариациями уровня депрессивности (Р>0.05). Последующий стратификационный анализ, проведенный среди мужчин, женщин, индивидов русской, татарской, удмуртской и башкирской этнической принадлежности, также не продемонстрировал ассоциаций с уровнем депрессивности.

Вторым этапом обработки результатов являлась оценка эффекта ген-средовых взаимодействий, учитывающего, наряду с генетическими вариантами, вовлеченность различных социальных параметров. Таким образом, было показано, что такие факторы, как «сезон рождения» и «порядок рождения» модулируют ассоциацию полиморфных локусов в гене $T N F$ с индивидуальным уровнем депрессивности. В частности, более низкий уровень депрессивности был более характерен для носителей минорного аллеля $r s 1041981^{*} A$, родившихся осенью, по сравнению с индивидами, рождёнными в другое время года ( $\left.\beta=-2.002 ; r^{2}=0.025 ; P=0.011 ; P_{F D R}=0.045\right)$. Предполагается, что вовлеченность "сезона рождения» в вариации депрессивности и других свойств личности может быть опосредована сезонными изменениями в частоте некоторых инфекционных заболеваний, различиями в рационе питания в период пренатального развития и другими особенностями. Данные фракторы могут оказывать влияние на возникновение врожденных структурных и функциональных изменений мозга, а также на уровень активности нейромедиаторных систем. Кроме того, было обнаружено, что носители аллеля $r s 1800629^{*} A$, являющиеся младшими из трёх или большего числа детей в семье, имели более высокие средние показатели депрессивности ( $\beta=3.667 ; r^{2}=0.057$; $\mathrm{P}=0.028)$. Обнаруженный эффрект может быть объяснен исходя из «теории истощения ресурсов», согласно которой каждый последующий ребенок требует от родителей больше ресурсов, а в условиях их дефицита (если индивид является младшим ребенком в семье) могут формироваться различия в уровне депрессивности, связанные со стрессовой чувствительностью, в зависимости от наличия определенного варианта rs1800629 в гене TNF [5].

Вывод. Таким образом, выявленные нами ассоциации уровня депрессивности с такими средовыми фракторами, как «сезон рождения» и «порядок рождения», могут указывать на возможные эпигенетические изменения, затрагивающие тонкую регуляцию генной экспрессии в онтогенезе, что требует проведения дальнейших исследований.

Работа выполнена в рамках государственного задания Минобрнауки РФ (№ АAАAA21-121011990119-1). Образцы ДНК взяты из ЦКП «Коллекция биологических материалов человека» ИБГ УФИЦ РАН, поддержанного Программой биоресурсных коллекций ФАНО России (соглашение № 007-030164/2).

\section{Литература}

1. Смулевич А. Б. Депрессии при психических и соматических заболеваниях // М.: Медицинское инфрормационное агентство, 2015. 640 с.

2. Kendler K. S., Gatz M., Gardner C. O., Pedersen N. L. A Swedish national twin study of lifetime major depression // Am. J. Psychiatry. 2006. V. 163(1). P. 109-114. DOI 10.1176/appi.ajp.163.1.109.

3. Давыдова Ю. Д., Еникеева Р. Ф., Казанцева А. В. и др. Генетические основы предрасположенности к депрессивным расстройствам // Вавиловский журнал генетики и селекции. 2019. Т. 23. № 4. С. 465-472. DOI 10.18699/VJ19.515. 
4. Мустафин Р. Н., Еникеева Р. Ф., Давыдова Ю. Д., Хуснутдинова Э. К. Роль эпигенетических фракторов в развитии депрессивных расстройств // Генетика. 2018. Т. 54. № 12. C. 1376-1389. DOI 10.1134/S001667581812010X.

5. Härkönen J. Birth Order effects on educational attainment and educational transitions in West Germany // Eur. Sociol. Rev. 2014. V. 30(2). P. 166-179. DOI 10.1093/esr/jct027.

The role of inflammatory cytokine genes in individual differences in depression level

Yu. D. Davydova ${ }^{1 *}$, A. V. Kazantseva ${ }^{1}$, R. F. Enikeeva ${ }^{1}$, R. N. Mustafin ${ }^{2}$, M. M. Lobaskova ${ }^{3}$, S.B. Malykh ${ }^{3}$, E.K. Khusnutdinova ${ }^{1}$

${ }^{1}$ Institute of Biochemistry and Genetics - Subdivision of the Ufa Federal Research Centre of the Russian Academy of Sciences

71 Prospekt Oktyabrya, 450054 Ufa, Republic of Bashkortostan, Russia.

${ }^{2}$ Bashkir State Medical University

3 Lenin Street, 450008 Ufa, Republic of Bashkortostan, Russia.

${ }^{3}$ Psychological Institute of Russian Academy of Education

9/4 Mokhovaya Street, 125009 Moscow, Russia.

*Email: julia.dmitrievna@list.ru

The present study aimed to assess the main effects of TNF (rs1041981, rs1800629), IL6 (rs1800795) and IL6R (rs2228145) gene polymorphisms together with G×E effects on individual differences in depression level in 1035 mentally healthy individuals with sex and ethnicity as covariates. As a result of statistical analysis we observed that birth season and order of birth significantly affected association of rs1041981 and rs1800629 and depression level.

Keywords: depression, depressiveness, inflammation, gene-environment interactions. 